\title{
ANALISA KOMPRESI CITRA DIGITAL MENGGUNAKAN METODE HADAMARD
}

\author{
Eva Haryanty, S.Kom. ${ }^{*}$
}

\begin{abstract}
ABSTRAK
Kompresi data adalah proses mengubah suatu input data menjadi data lain dengan format berbeda dan ukuran yang lebih kecil, atau proses pengkodean dari suatu data untuk mengurangi kebutuhan akan media penyimpanan. Salah satu jenis file yang paling banyak membutuhkan proses kompresi adalah file citra.

Tujuan dari penelitian kali ini adalah menganalisa kembali hasil penelitian yang telah dilakukan oleh Yudi Prayudi dan Ali Facruddin, dosen pada salah satu universitas di Yogyakarta.

Berdasarkan hasil percobaan yang dilakukan oleh Yudi Prayudi dan Ali Fachruddin, didapat hasil bahwa kompresi citra dengan menggunakan matriks 4x4 membutuhkan waktu yang lebih singkat dibandingkan dengan menggunakan matriks $8 \times 8$.
\end{abstract}

Kata Kunci: Kompresi data, file citra.

\section{LATAR BELAKANG}

Salah satu masalah yang terus berkembang sejalan dengan berkembangnya dunia komputer adalah terkait dengan penanganan data yang berukuran besar. Masalah ini muncul karena hardware yang digunakan terkait dengan penanganan data kurang mampu mengikuti perkembangan ukuran data yang demikian besar. Salah satu kajian yang terkait dengan penanganan ini adalah kompresi data.

Kompresi data adalah proses mengubah suatu input data menjadi data lain dengan format berbeda dan ukuran yang lebih kecil, atau proses pengkodean dari suatu data untuk mengurangi kebutuhan akan media penyimpanan. Salah satu jenis file yang paling banyak membutuhkan proses kompresi adalah file citra.

Salah satu metode yang dapat digunakan untuk menghasilkan file kompresi citra adalah dengan metode Transformasi Hadamard. Metode transformasi Hadamard merupakan suatu metode transformasi dengan menggunakan matriks bujursangkar yang berisikan hanya 1 dan -1 yang memiliki dua atau lebih kolom atau baris yang terletak berhadapan dimana setengahnya bagian memiliki tanda yang sama dan setengah bagian lainnya memiliki tanda yang berlawanan. Dengan menggunakan metode ini, suatu citra biner digunakan sebagai input. Citra tersebut dianggap sebagai suatu matrik dengan jumlah kolom sama dengan lebar citra dan jumlah baris sama dengan tinggi citra. Masing - masing nilai hitam dan putih (B dan W) dari setiap piksel citra selanjutnya dihitung secara tersendiri sehingga akan diperoleh 2 buah matriks, masing - masing dengan kolom x dan baris $\mathrm{y}$.

\footnotetext{
* Staf Pengajar Program Studi S1-Teknik Informatika IKADO
} 


\section{TINJAUAN PUSTAKA}

Dalam bab ini akan diuraikan teori-teori penunjang dari pembahasan masalah, diantaranya konsep dasar citra, pengolahan citra, kompresi citra dan metode yang digunakan dalam kompresi citra.

\subsection{Konsep Dasar Citra}

Citra merupakan dimensi spatial yang berisi informasi warna dan tidak bergantung pada waktu. Citra merupakan sekumpulan titik-titik dari gambar, yang disebut pixel (picture element). Titik-titik tersebut menggambarkan posisi koordinat dan mempunyai intensitas yang dapat dinyatakan dalam bilangan. Intensitas ini menunjukan warna citra melalui penjumlahan (Red, Green, Blue /RGB).

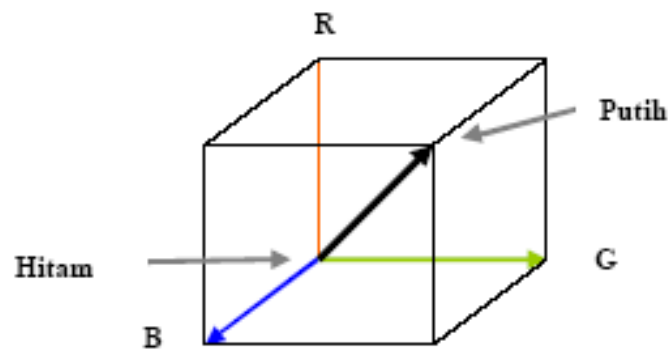

Gambar Koordinat RGB

Pada file bitmap, dapat menampung citra yang berukuran 1, 4, 8 atau 24 bit untuk setiap pixelnya. Citra berukuran 24 bit merupakan warna dasar. Suatu pixel yang berukuran 24 bit terdiri dari $3 \times 1$ byte (masing-masing 8 bit) yang masing-masing mewakili komponen warna Red, Green, dan Blue yang merupakan tiga warna primer. Nilai setiap byte berada pada rentang $0-255$.

Selain file bitmap, juga terdapat file JPEG dan PNG. File JPEG adalah format penyimpanan gambar yang banyak digunakan untuk menyimpan gambar-gambar dengan ukuran lebih kecil. Karakteristik JPEG adalah mampu menayangkan warna dengan kedalaman 24-bit truecolor, mengkompresi gambar dengan sifat lossy. Umumnya JPEG digunakan untuk menyimpan gambar-gambar hasil foto. Sedangkan file PNG adalah salah satu format penyimpanan citra yang menggunakan metode pemadatan yang tidak menghilangkan bagian dari citra tersebut (lossless compression). Untuk keperluan pengolahan citra, meskipun format PNG bisa dijadikan alternatif selama proses pengolahan citra, karena format ini selain tidak menghilangkan bagian dari citra yang sedang diolah (sehingga penyimpanan berulang ulang dari citra tidak akan menurunkan kualitas citra) namun format JPEG masih menjadi pilihan yang lebih baik.

\subsection{Pengolahan Citra Digital}

Pengolahan citra merupakan proses pengolahan dan analisis citra yang banyak melibatkan persepsi visual. Proses ini mempunyai ciri data masukan dan informasi keluaran yang berbentuk citra. Istilah pengolahan citra digital secara umum didefinisikan sebagai pemrosesan citra dua dimensi dengan komputer. Dalam definisi yang lebih luas, pengolahan citra digital juga mencakup semua data dua dimensi. Citra digital adalah barisan bilangan nyata maupun kompleks yang diwakili oleh bit-bit tertentu. 
Frase pengolahan citra digital sering dikaitkan dengan pemrosesan gambar dua dimensi. Untuk sebuah pengolahan citra digital yang sederhana, tingkat pemrosesannya dapat dijabarkan sebagai berikut :

1. Sebuah citra digital dalam bentuk transparansi, slide, foto, ataupun chart didigitalkan terlebih dahulu dan disimpan sebagai sebuah matriks yang berisikan digit biner dalam memori komputer.

2. Citra kemudian dapat diproses dan ditampilkan pada monitor yang mempunyai resolusi tinggi.

3. Untuk tampilan, citra disimpan dalam sebuah penampung memori yang dapat diakses dengan cepat yang akan me-refresh monitor dengan 30 frame/detik untuk memproduksi sebuah tampilan kontinyu yang dapat dilihat dengan jelas.

4. Komputer mikro maupun komputer mini digunakan untuk berkomunikasi dan mengendalikan semua proses digitalisasi, penyimpanan, dan operasi tampilan melalui komputer jaringan.

\subsection{Kompresi Citra}

Kompresi citra adalah aplikasi kompresi data yang dilakukan terhadap citra digital dengan tujuan untuk mengurangi redundansi dari data - data yang terdapat dalam citra sehingga dapat disimpan atau ditransmisikan secara efisien.

\subsubsection{Teknik Kompresi Citra}

Teknik kompresi pada citra dibagi menjadi 2 bagian :

a. Lossy Compression

- Ukuran citra menjadi lebih kecil dengan menghilangkan beberapa informasi dalam citra asli.

- Teknik ini mengubah detail warna pada citra menjadi lebih sederhana tanpa perbedaan yang mencolok dalam pandangan manusia, sehingga ukurannya menjadi lebih kecil.

- Biasanya digunakan pada citra foto atau image lain yang tidak terlalu memerlukan detail citra, dimana kehilangan bit rate foto tidak berpengaruh pada citra.

b. Lossless Compression

- Teknik kompresi citra dimana tidak ada satupun informasi citra yang dihilangkan. Biasa digunakan pada citra medis.

\subsubsection{Metode Kompresi}

Ada beberapa metode kompresi citra yang umum, diantaranya Discrete Wavelets Transform dan Discrete Cosinus Transform.

\section{- Discrete Cosinus Transform}

Discrete Cosinus Transform di divided menjadi blok-blok kecil dengan ukuran yang tetap, kemudian dikonversikan dari domain spatial menjadi domain frekuensi. Konversi ke domain frekuensi ini sangat menguntungkan untuk proses selanjutnya. Discrete Cosinus Transform (DCT) adalah aplikasi untuk kompresi citra yang dipelopori oleh Chen dan Pratt (1984).

- Discrete Wavelets Transform

Wavelet merupakan gelombang mini (small wave) yang mempunyai kemampuan mengelompokan energi citra terkosentrasi pada sekelompok 
kecil koefisien, sedangkan kelompok koefisien lainnya hanya mengandung sedikit energi yang dapat dihilangkan tanpa mengurangi nilai informasinya.

\section{ANALISA PROGRAM DAN PEMBAHASAN}

Berdasar pengertian transformasi metode Hadamard, maka secara garis besar proses untuk melakukan kompresi citra untuk tipe citra warna dan citra biner adalah sebagaimana pada gambar dibawah :

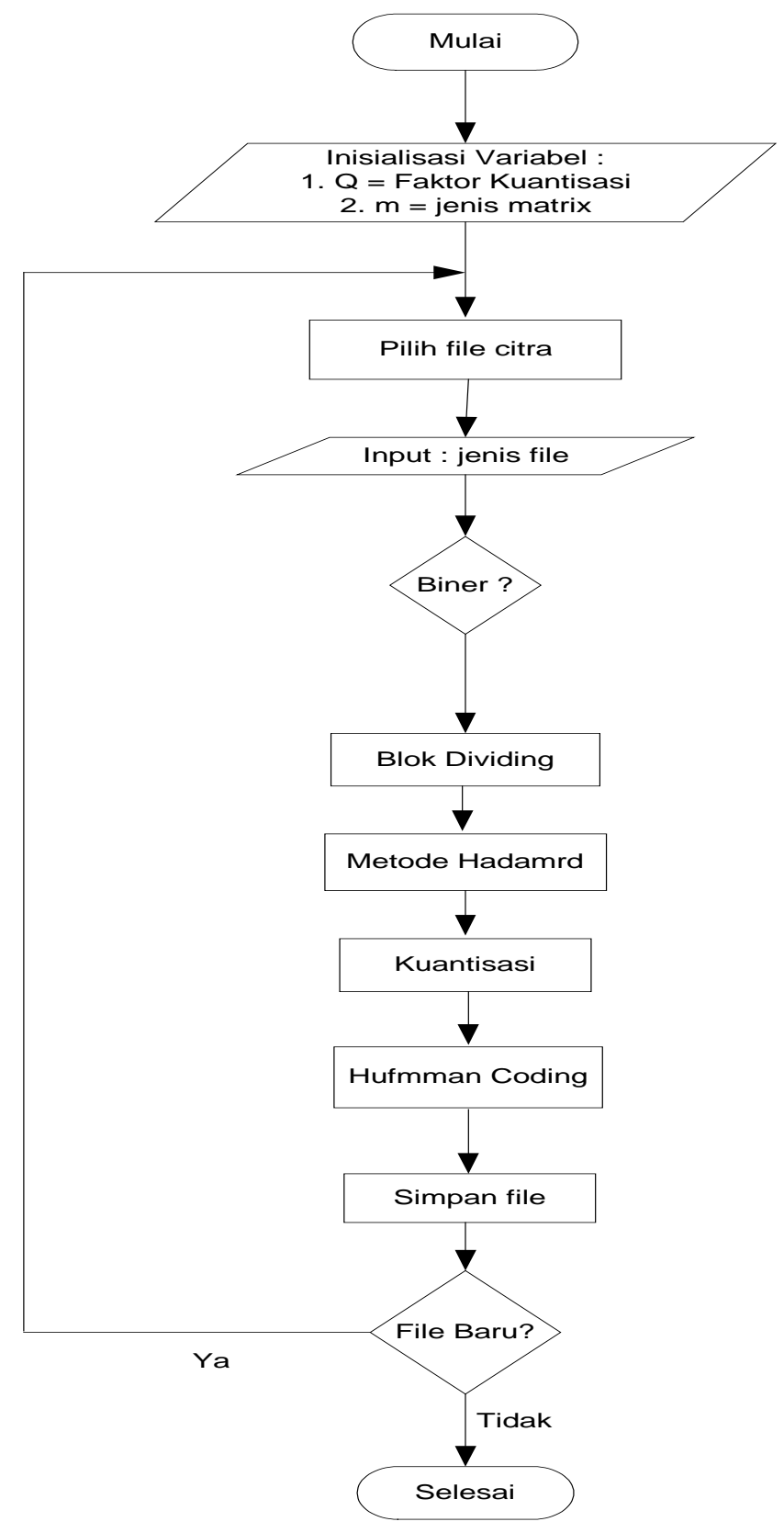

Gambar Diagram Alir Kompresi Citra

Proses awal dari kompresi adalah melakukan Block Dividing, yaitu membagi matriks citra menjadi sub-sub matriks yang berukuran lebih kecil agar lebih mudah diproses. Syarat sub-matriks yang harus dipenuhi antara lain : 
- Jumlah baris dan kolom sama (Matriks Bujur sangkar).

- Jumlah baris atau kolom merupakan bilangan $2^{\mathrm{n}}$, misal 2, 4, 8, 16, dst.

Ada 2 ukuran matriks yang sering digunakan,yaitu matriks ukuran $4 \times 4$ dan matriks ukuran 8x8. Ukuran Block Dividing yang dipakai dapat menentukan lamanya proses, berhubungan dengan jumlah operasi matematika yang dilakukan, serta menentukan kualitas citra yang dihasilkan. Pada saat block dividing dilakukan, ada kemungkinan terdapat sisa baris atau kolom yang jumlahnya kurang dari ukuran block.

\section{ANALISA HASIL}

Salah satu pengujian terhadap program yang telah dibuat oleh Yudi Prayudi dan Ali Fachruddin menggunakan delphi adalah berdasar waktu yang dibutuhkan (running time) untuk melakukan kompresi. Dari pengujian yang dilakukan, untuk faktor kuantisasi yang berbeda, didapatkan hasil bahwa waktu yang dibutuhkan untuk melakukan kompresi pada citra yang sama tidak jauh berbeda seperti tampak pada Tabel.

Tabel Running Time Kompresi Citra dengan Matriks 4x4

\begin{tabular}{|l|c|c|c|c|}
\hline \multirow{2}{*}{ Nama Citra } & \multirow{2}{*}{ Dimensi Citra } & \multicolumn{3}{|c|}{ Waktu Kompresi (s) } \\
\cline { 3 - 5 } & & $\mathrm{Q}=1$ & $\mathrm{Q}=1,5$ & $\mathrm{Q}=2$ \\
\hline alu & $572 \times 392$ & 1,262 & 1,242 & 1,243 \\
\hline arctic hare & $594 \times 400$ & 1,321 & 1,322 & 1,282 \\
\hline baboon & $512 \times 512$ & 1,442 & 1,452 & 1,432 \\
\hline bear & $394 \times 600$ & 1,312 & 1,302 & 1,362 \\
\hline newyork & $518 \times 744$ & 2,674 & 2,653 & 1,302 \\
\hline waterfall & $842 \times 571$ & 2,603 & 2,624 & 2,683 \\
\hline brandyrose & $800 \times 600$ & 2,404 & 2,373 & 2,604 \\
\hline wildflowers & $594 \times 400$ & 1,513 & 1,492 & 2,382 \\
\hline bandon & $610 \times 403$ & 1,372 & 1,452 & 1,432 \\
\hline
\end{tabular}

Selain itu dapat diamati pula bahwa waktu yang dibutuhkan untuk kompresi dengan menggunakan matriks 4 x 4 lebih sedikit dibandingkan dengan waktu yang dibutuhkan untuk melakukan kompresi dengan menggunakan matriks 8 x 8 . Sebagai contoh, fakotr untuk kuantisasi $=1$, waktu yang dibutuhkan untuk kompresi citra ALU.BMP dengan menggunakan matrik 4 x 4 hanya 1,262 detik sedangkan waktu yang dibutuhkan dengan menggunakan matriks 8 x 8 adalah 1,492. Hasil perbandingan waktu yang dibutuhkan untuk kompresi dengan faktor kompresi citra lainnya dapat dilihat pada Tabel.

Tabel Perbandingan Running Time Kompresi Citra $(\mathrm{Q}=1)$

\begin{tabular}{|l|c|c|c|}
\hline \multirow{2}{*}{ Nama Citra } & \multirow{2}{*}{ Dimensi Citra } & \multicolumn{2}{c|}{ Waktu Kompresi (s) } \\
\cline { 3 - 4 } & & Matrik $4 \times 4$ & Matrik $8 \times 8$ \\
\hline alu & $572 \times 392$ & 1,262 & 1,492 \\
\hline arctic hare & $594 \times 400$ & 1,321 & 1,562 \\
\hline baboon & $512 \times 512$ & 1,442 & 1,713 \\
\hline bear & $394 \times 600$ & 1,312 & 1,583 \\
\hline newyork & $518 \times 744$ & 2,674 & 3,195 \\
\hline waterfall & $842 \times 571$ & 2,603 & 3,094 \\
\hline brandyrose & $800 \times 600$ & 2,404 & 2,854 \\
\hline
\end{tabular}


Tabel Perbandingan Running Time Kompresi Citra (Q=1) (Lanjutan)

\begin{tabular}{|l|c|c|c|}
\hline \multirow{2}{*}{ Nama Citra } & \multirow{2}{*}{ Dimensi Citra } & \multicolumn{2}{c|}{ Waktu Kompresi (s) } \\
\cline { 3 - 4 } & & Matrik $4 \times 4$ & Matrik $8 \times 8$ \\
\hline wildflowers & $594 \times 400$ & 1,513 & 1,782 \\
\hline bandon & $610 \times 403$ & 1,372 & 1,632 \\
\hline
\end{tabular}

Selanjutnya adalah pengujian terhadap ukuran file hasil kompresi. Tabel Perbandingan Ukuran File Hasil Kompresi Citra menunjukkan hasil akhir kompresi untuk nilai quantisasi yang berbeda.

Tabel Perbandingan Ukuran File Hasil Kompresi Citra

\begin{tabular}{|l|c|c|c|c|}
\hline \multirow{2}{*}{ Nama Citra } & \multirow{2}{*}{ Dimensi Citra } & \multicolumn{3}{c|}{ Ukuran File (byte) } \\
\cline { 3 - 5 } & & $\mathrm{Q}=1$ & $\mathrm{Q}=1,5$ & $\mathrm{Q}=2$ \\
\hline alu & $572 \times 392$ & 236,891 & 196,807 & 173,762 \\
\hline arctic hare & $594 \times 400$ & 128,506 & 121,377 & 116,995 \\
\hline baboon & $512 \times 512$ & 236,675 & 196,112 & 174,221 \\
\hline bear & $394 \times 600$ & 164,567 & 146,109 & 136,334 \\
\hline newyork & $518 \times 744$ & 416,194 & 351,937 & 315,095 \\
\hline waterfall & $842 \times 571$ & 280,720 & 258,516 & 246,234 \\
\hline brandyrose & $800 \times 600$ & 249,437 & 222,387 & 209,093 \\
\hline wildflowers & $594 \times 400$ & 330,242 & 277,501 & 242,550 \\
\hline bandon & $610 \times 403$ & 153,059 & 139,639 & 132,383 \\
\hline
\end{tabular}

Selain pengujian diatas, Yudi Paryudi dan rekannya juga melakukan pengujian yang bertujuan untuk membandigkan ukuran file hasil kompresi dengan menggunakan perangkat lunak lain yang sudah ada. Dalam penelitian yang dilakukan, perangkat lunak yang dipakai oleh mereka sebagai pembanding adalah Adobe Photoshop 7.0. Adapun jenis file kompresi yang dipakai sebagai pembanding adalah JPEG dan PNG.

Untuk melihat kualitas kompresi yang dilakukan, dilakukan pengujian terhadap nilai Mean Square Error (MSE) terhadap citra hasil kompresi. Dari hasil pengujian yang dilakukan, didapatkan hasil bahwa semakin besar nilai fakto kuantisasi yang dipakai untuk kompresi maka nilai MSE semakin besar pula. Semakin besarnya nilai MSE berarti kualitas dari citra hasil kompresi semakin berkurang.

Setalah melihat hasil kompresi yang dilakukan oleh Yudi Paryudi dan Ali Facruddin, dimana citra yang dipakai oleh mereka adalah citra warna, maka sesuai dengan tugas khusus kali ini, beberapa citra yang dipakai untuk diuji, dirubah tipenya menjadi citra biner atau citra hitam putih.

Uji coba dilakukan pada satu gambar saja. Perbandingan dilihat pada ukuran file sebelum diconvert menjadi citra biner dan sesudah diconvert menjadi citra biner atau citra hitam putih.

Gambar dibawah ini adalah salah satu contoh gambar berwarna yang digunakan dalam penelitian Prayudi dan Fachruddin. 


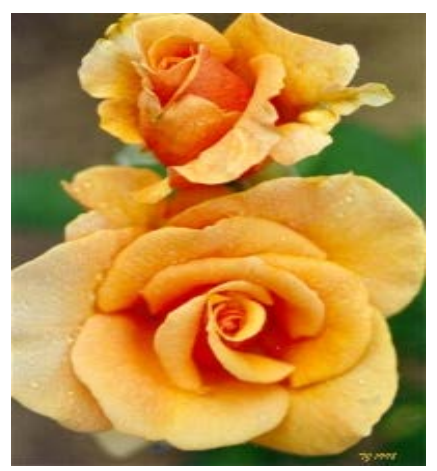

Gambar Citra Brandyrose (asli)

Dan gambar dibawah ini adalah hasil convert menjadi citra hitam putih.

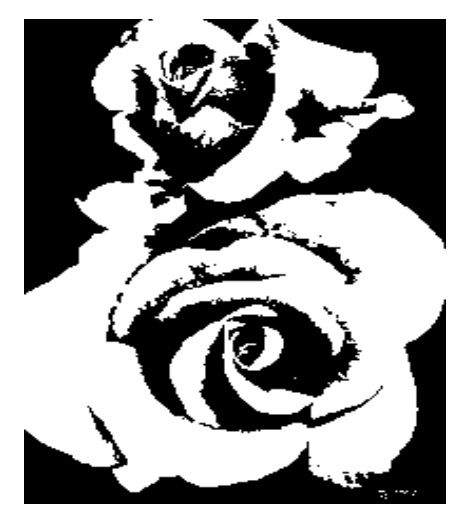

Gambar Citra Brandyrose (format hitam putih)

Dari hasil diatas, diketahui bahwa tipe citra warna jika diubah menjadi citra biner, ukuran filenya tetap sama. Namun, jika dilakukan kompresi pada citra tersebut, hasilnya belum tentu akan sama, karena faktor yang membedakan nilai kompresi tidak hanya ukuran file.

\section{KESIMPULAN DAN SARAN}

Berdasarkan hasil percobaan yang dilakukan oleh Yudi Prayudi dan Ali Fachruddin, didapat hasil bahwa kompresi citra dengan menggunakan matriks 4x4 membutuhkan waktu yang lebih singkat dibandingkan dengan menggunakan matriks 8x8. Selain itu berdasar ukuran hasil kompresi, kompresi dengan menggunakan matriks 8x8 menghasilkan ukuran file yang lebih kecil dibandingkan menggunakan matriks 4x4. Perbandingan file hasil kompresi antara perangkat lunak Adobe Photoshop dengan menggunakan metode hadamard, ternyata menunjukkan penggunaan metode hadamard memberikan ukuran file yang lebih kecil dibandingkan dengan file hasil kompresi menggunakan perangkat lunak Adobe Photoshop.

Hasil lain juga menunjukkan nilai MSE pada matriks 4x4 lebih kecil dibandingkan dengan matriks 8x8. Dan dari hasil percobaan yang ditambahkan, ternyata ukuran file citra sebelum dan sesudah diubah formatnya, memiliki ukuran file yang sama. Namun dalam hal hasil kompresi, hasilnya belum tentu akan sama. 
Penelitian dapat dilanjutkan untuk mengetahui hasil kompresi citra pada citra yang telah diubah formatnya menjadi citra biner. Sehingga dapat diketahui apakah hasil kompresi pada citra yang sama dengan format yang berbeda memiliki hasil kompresi yang sama.

\section{DAFTAR PUSTAKA}

Prayudi, Yudi, Ali Facruddin, Analisa Kompresi Citra Digital Menggunakan Metode Hadamard, Teknik Industri FT Universitas Islam Indonesia.

Achamd, Balza, dan Kartika Firdausy, Teknik Pengolahan Citra Digital Menggunakan Delphi, Yogyakarta : Ardi Publishing, 2005

Mandala, Jani F., Pemanfaatan Transformasi Wavelet Citra Wajah, Institut Teknologi Banding, 2003

Multimedia 7.pdf, Kuliah Semester Genap, Fakultas Teknik Informatika Universitas Kristen Duta Wacana, 2005-2006

Tharom, Tabratas, Pengolahan Citra Pada Mobil robot, IlmuKomputer.com, 2003

Linda, Agustina, Penerapan Region of Interest (ROI) pada Metode Kompresi JPEG2000, Departemen Teknik Informatika, Institut Teknologi Bandung.

Jain, A. K., Fundamentals of Digital Image Processing, Prentice Hall, New Delhi, 1995. 